\title{
ANÁLISE DA JURISPRUDÊNCIA DO SUPERIOR TRIBUNAL DE JUSTIÇA SOBRE O MEIO AMBIENTE E A CULPA NA RESPONSABILIDADE ADMINISTRATIVA POR DANO AMBIENTAL PELA EMPRESA PRIVADA
}

\author{
Tamara Cristiane Geiser ${ }^{1}$ \\ Mateus Bertoncini ${ }^{2}$
}

\section{Resumo:}

O presente trabalho tem o escopo, empregando o método dedutivo, de averiguar a responsabilidade administrativa por dano ambiental, no sentido de estudar se esta deve ser vista sob a ótica objetiva ou subjetiva. O estudo percorre o lugar onde se situa o meio ambiente no ordenamento, como um bem jurídico tutelado na perspectiva dos direitos fundamentais e do princípio da dignidade da pessoa humana, e se estende para a análise do conceito de dano ambiental e as responsabilidades que recaem sobre o agente poluidor, especialmente quando se tratar de empresa poluidora.

Palavras-chave: Responsabilidade administrativa por dano ambiental, agente poluidor, empresa poluidora, responsabilidade objetiva, responsabilidade subjetiva.

\section{ANALYSIS OF THE JURISPRUDENCE OF THE SUPERIOR COURT OF JUSTICE ON THE ENVIRONMENT AND GUILTY IN ADMINISTRATIVE RESPONSIBILITY FOR ENVIRONMENTAL DAMAGE FOR THE PRIVATE COMPANY}

\begin{abstract}
:
The present study has the scope, employing the deductive method, to analyze the administrative responsibility for environmental damages, in the sense of studying whether it should be seen from an objective or subjective perspective. The study covers the status where the unorganized environment is located, as a legal right protected from the perspective of fundamental rights and the principle of human dignity, and extends to an analysis of the concept of environmental damage and how those who report on the polluter agente, especially when it comes to the polluting company.
\end{abstract}

Keywords: The administrative responsibility for environmental damages, polluting agente, polluting company, subjective

\section{INTRODUÇÃO}

\footnotetext{
${ }^{1}$ Advogada. Mestre em Direito Empresarial e Cidadania pelo Centro Universitário Curitiba - UNICURITIBA (2020). Especialista em Direito Constitucional pela Academia Brasileira de Direito Constitucional (2015).

${ }^{2}$ Doutor em Direito do Estado pela Universidade Federal do Paraná (2004). Professor do Corpo Permanente do Programa de Mestrado e Doutorado em Direito Empresarial e Cidadania do Centro Universitário Curitiba UNICURITIBA. Professor Titular de Direito Administrativo da Faculdade de Direito de Curitiba - UNICURITIBA. Professor de Direito Administrativo da Fundação Escola do Ministério Público do Paraná - FEMPAR.
} 
Diante dos grandes desastres ambientais, como o rompimento das barragens em Mariana (2015) e em Brumadinho (2019), bem como as atuais queimadas no Pantanal (2020), não se permite que a responsabilização por danos ambientais seja negligenciada por nenhuma das esferas destacadas pela Constituição Federal.

O presente artigo busca abordar o dano ambiental sob a ótica das espécies de responsabilidades que devem ser apuradas em caso do sinistro contra o meio ambiente. Além de se distinguir os tipos de responsabilidade que o ordenamento jurídico prevê, torna-se importante trazer ao debate acadêmico a responsabilidade administrativa, a fim de investigar, mediante o emprego do método dedutivo, se esta deve ser objetiva ou subjetiva.

No Texto Constitucional, o $\$ 3^{\circ}$ do artigo 225 destaca que as condutas e atividades consideradas lesivas ao meio ambiente sujeitarão os infratores, pessoas físicas ou jurídicas, a sanções penais e administrativas, independentemente da obrigação de reparar os danos causados.

Da norma, extrai-se a tríplice responsabilidade, em caso de dano ambiental - penal, administrativa e civil.

Especificamente no que concerne à responsabilidade administrativa, o debate que surge na doutrina e na jurisprudência está vinculado à sua natureza subjetiva ou objetiva, para aplicação das sanções correspondentes.

A matéria, em princípio, teria sido pacificada pelo Superior Tribunal de Justiça, em recente julgado (Superior Tribunal de Justiça. EREsp 1.318.051 - RJ - 2012/0070152-3, 2019), ao analisar sobre a responsabilidade administrativa por dano ambiental da empresa privada.

Contudo, considerando a controvérsia doutrinária e jurisprudencial existente sobre o tema, a presente pesquisa adentra neste cenário a fim de buscar resposta filosófica (princípio responsabilidade), principiológica (princípios constitucionais do meio ambiente), sistêmica e finalística quanto à questão principal do estudo: a responsabilidade administrativa por dano ambiental da pessoa jurídica, em especial a empresa privada, é objetiva ou subjetiva?

\section{DIRETOS FUNDAMENTAIS E MEIO AMBIENTE}

O Relatório "Nosso Futuro Comum" - também conhecido como "Relatório de Bruntdland" - de 1987, da Comissão Mundial sobre o Meio Ambiente e Desenvolvimento da Organização das Nações Unidas (1991, p. 161), reconheceu a dependência existencial em relação à biosfera e destacou o quadro de desigualdade social na base do projeto de desenvolvimento econômico e social.

Os novos desafios que se colocam na contemporaneidade para a sociedade, Estado e Direito, são enfrentados com o objetivo de manutenção da vida - e da qualidade desta para todos os níveis sociais - no planeta, o que carrega a problemática do direito ambiental posta no seio da sociedade industrial: a degradação ambiental.

A proposta de elevar o meio ambiente ao patamar de direito fundamental sugere um novo paradigma, a fim de se adotar um novo modelo de produção, atendendo à livre 
iniciativa, a livre concorrência e propriedade privada, mas que se tenha o parâmetro a sustentabilidade (PADILHA, 2010, p. 161).

Tendo em vista os desafios gerados pela crise ecológica e pela sociedade tecnológica e industrial, fez-se necessário o surgimento de um novo modelo, superando os paradigmas antecedentes, respectivamente do Estado Liberal e do Estado Social.

O novo modelo de um Estado Socioambiental objetiva enfatizar a convergência das agendas social e ambiental em um mesmo projeto jurídico político para o desenvolvimento.

De acordo com Sarlet (2014, p. 295), a miséria e a pobreza caminham juntas com a degradação ambiental, expondo as populações de baixa renda a violações a sua dignidade.

Assume particular importância a proposta de uma proteção integrada dos direitos sociais e dos direitos ecológicos, agrupados sob o rótulo genérico de direitos fundamentais socioambientais ou direitos econômicos, sociais, culturais e ambientais. Por intermédio destes busca assegurar condições mínimas de qualidade de vida, e, sendo menos que essas, poderá ainda haver vida, mas essa não será digna de ser vivida.

A integração e interdependência dos direitos sociais e da proteção do ambiente, refere um dos esteios da noção de desenvolvimento sustentável (SARLET, 2014, p. 295).

Na Constituição Federal de 1988 não há consagração expressa quanto ao Estado Social e Ambiental, o que, no entanto, não significa dizer que não possa ser definido como tal. Por meio de análise dos objetivos fundamentais, postos no artigo $3^{\circ}$ da Constituição Cidadã, pode-se observar o extenso catálogo de direitos sociais de trabalhadores, princípios de ordem econômica, assim como a conformação do sistema constitucional de seguridade social e da ordem social como um todo.

Na questão ambiental se aplica o mesmo raciocínio, visto que a constitucionalização da proteção ambiental foi detalhada no artigo 225 , inclusive como um direito e dever fundamental.

O novo modelo traz a superação do Estado Social, após a Segunda Guerra Mundial, visto que trouxe uma maior preocupação com dignidade humana, comprometendo-se com a estabilização dos riscos da degradação ambiental. Traz a dimensão ecológica ao princípio da dignidade da pessoa humana (SARLET, 2014, p. 55).

A institucionalização das demandas ecológicas passa pela celeuma dos direitos sociais como premissa para uma condição de cidadania. Trata-se da dimensão integrativa e interdependente dos direitos com o fulcro de uma tutela integral de promoção a dignidade da pessoa humana, formatando-se os direitos fundamentais socioambientais.

O surgimento do constitucionalismo socioambiental avança no sentido de corrigir o quadro de desigualdade e de degradação humana (no que se inclui as penalidades administrativas), com a finalidade de conceder acesso às condições mínimas de bem-estar (SARLET, 2014, p. 56).

\subsection{Dimensão ecológica da dignidade da pessoa humana}


Desde o surgimento das primeiras constituições, os direitos fundamentais se modificaram na toada da instituição do modelo de Estado implementado.

Em um primeiro momento os direitos fundamentais foram instituídos com cunho individualista no âmbito do Estado Liberal, sendo designados de direitos de primeira dimensão, consubstanciando garantias de liberdade contra o ente estatal. Tratava-se de direitos de defesa, buscando uma atuação de não intervenção do Estado, privilegiando a autonomia da vontade em face do Poder Público.

Posteriormente, o impacto gerado pela Revolução Industrial trouxe a necessidade de se implementar direitos sociais, envolvendo garantias sociais, econômicas e culturais. Denominam-se, assim, os direitos de segunda dimensão, os quais buscam a atuação positiva do Estado, com o fito de proporcionar um direito do bem-estar social. (SARLET, 2014, p. 320).

No entanto, para além da necessidade de proteção dos direitos individuais do bemestar social, subsistem direitos que transcendem a esfera do indivíduo, cuida-se dos direitos de solidariedade, cuja titularidade pertence a uma coletividade indeterminada (SARLET, 2014, p. 321). Cuida-se, dentre outros, dos direitos à paz, à autodeterminação dos povos, ao desenvolvimento, ao meio ambiente e qualidade de vida.

$\mathrm{O}$ direito de viver em um ambiente sábio, equilibrado e seguro conforma com o conteúdo de um direito fundamental de solidariedade (SARLET, 2014, p. 81), ampliando o âmbito de proteção e promoção da dignidade.

O desafio posto, portanto, concentra-se na dimensão ecológica da dignidade da pessoa humana, considerando os riscos ambientais que a contemporaneidade traz consigo.

A partir do conceito de dignidade da pessoa humana e considerando os desafios ecológicos para se alcançar a qualidade do bem-estar, tem-se uma nova moldura da dignidade da vida em geral.

De acordo com a lição de Benjamin (2011, p. 89), inicialmente se faz necessário compreender a condição humana impõe a qualidade de atribuir responsabilidade, mesmo que unilateralmente, não apenas em favor dos seres humanos. Tal premissa leva a concluir, conforme o autor, que a vida e a natureza vão além da humana e do seu microcosmos. Até mesmo porque a natureza de modo amplo, existe antes mesmo da humanidade.

A reflexão proposta por Sarlet consiste no reconhecimento de uma dignidade, com deveres jurídico-constitucionais de proteção da dignidade não humana e das futuras gerações (SARLET, 2014, p.81).

A premissa kantiana (KANT, 1781) colocava o ser humano como o fim (o sujeito) em si, e não como meio (ou objeto), em qualquer relação, tanto entre particulares quanto com o Estado. No entanto, em tal visão é possível se questionar o excesso de antropocentrismo relacionado à visão filosófica ocidental.

Confrontando com os valores ecológicos que regem as relações contemporâneas e as bases éticas mais atuais, vislumbra-se a necessidade de proteção e promoção da vida em si (e não apenas à do ser humano). 
Supera-se, a partir do sustentáculo da dimensão ecológica de dignidade, a concepção de que o princípio deve alcançar apenas a vida humana, ampliando-se à contemplação de todas as formas de vida (SARLET, 2014, p. 83).

A convalidação da proteção ambiental, na esfera dos direitos fundamentais e o reconhecimento da qualidade de vida como elemento normativo integrante do princípio da dignidade da pessoa humana, acarreta a necessidade de uma reformulação conceitual da dignidade em sintonia com a demanda ecológica.

Discute-se uma nova perspectiva moral que possibilita reconhecer dos direitos próprios da Natureza, no sentido de se definir um "fim em si mesmo", ultrapassando a o campo meramente humano (SARLET, 2014, p. 91).

Nesta linha, Benjamin (2008, p. 49) defende a superação do antropocentrismo por ser insuficiente ao meio ambiente porque a tutela ambiental vem abandonando a rigidez antropocêntricas, alcançando uma visão mais ampla, de caráter biocêntrico. Propõe-se a amparar a vida em todas as suas bases, pois nem sempre a degradação uma espécie afeta, de modo visível e calculável, a saúde humana.

O artigo 225, §1 ${ }^{\circ}$, VII, da Constituição Federal de 1988 assevera que todos têm direito ao meio ambiente ecologicamente equilibrado, bem de uso comum do povo e essencial à sadia qualidade de vida, impondo-se ao Poder Público e à coletividade o dever de defendêlo e preservá-lo para as presentes e futuras gerações. E para assegurar a efetividade desse direito, incumbe ao ente estatal, dentre outras atribuições, proteger a fauna e a flora, vedadas, na forma da lei, as práticas que coloquem em risco sua função ecológica, provoquem a extinção de espécies ou submetam os animais a crueldade.

A normativa mencionada aponta ao reconhecimento constitucional do valor inerente a outras formas de vida não humanas, denotando uma proteção inclusive contra a ação humana, o que demonstra a preocupação de proteção não apenas da vida do ser humano.

A ampliação da noção ecológica da dignidade da vida sinaliza para uma releitura o contrato social em direção à tipificação de contrato ecológico, a fim de se ampliar à natureza o espaço protetivo estatal.

Os valores fundamentais de todas as dimensões (liberdade, igualdade $\mathrm{e}$ solidariedade), de acordo com Sarlet (2014, p. 108), devem ser ampliados para além do aspecto humano, para se alcançar um nível moral e cultural mais profundo, revelando um alcance da dignidade da vida em geral.

Portanto, a concepção não reducionista do princípio da dignidade da pessoa humana, vislumbra um reconhecimento multidimensional da vida, trazendo a amplificação da dimensão do princípio, no sentido de abarcar a preocupação de questões de qualidade ambiental, o que inclui todas as formas de vida, e não apenas a vida humana.

Em se tratando, a dignidade da pessoa humana e o meio ambiente, de direitos fundamentais - que ultrapassam a esfera da vida humana -, e considerando o caráter subjetivo e objetivo; negativo e positivo de tais garantias, a responsabilidade ambiental perpassa tanto pelo Estado, quanto pelo particular, sendo este último o objeto de concentração do presente estudo. 


\section{DESENVOLVIMENTO SUSTENTÁVEL}

A evolução da ciência e dos processos produtivos inerentes à industrialização são fatores que geram riscos à humanidade e ao meio ambiente, pela sua exposição imediata e pela reposição de contaminações anteriores (ALENCASTRO, 2012, p. 22).

Elaborada em 1986 pelo alemão Ulcri Beck (2011, p. 23), a teoria da sociedade de risco foi formulada para demonstrar que a produção de riquezas vem acompanhada sistematicamente de produção de riscos (NONINO; FERREIRA, 2016, p. 238-258).

A sociedade de risco se apresenta em dois estágios. Em um primeiro momento os riscos do desenvolvimento foram aceitos em tom de aventura e ousadia, no sentido de que muitas descobertas do homem ocorreram em virtude da experiência aventureira e ousada deste, utilizando-se a máxima, in dúbio pro progresso (REIS; BAPTISTA SILVA CARICATI; GIUBLIN, 2018). Em um segundo momento, surge a acentuação dos riscos da sociedade industrial e o assunto passou a ocupar os debates e os conflitos, onde se envolviam entes públicos e a iniciativa privada.

Os acidentes ambientais elencados demonstram a sociedade de risco em que vivemos, na qual o crescimento e o progresso, com desenvolvimento tecnológico, são narrativas que imperam (BODNAR, 2016, p. 977) e têm prevalecido sobre a efetiva preocupação com a qualidade de vida e do meio ambiente.

Milhares de vidas (no sentido amplo, abrangendo a vida humana, animal e vegetal) foram perdidas em razão dos desastres ambientais. Além das mortes, diversas sequelas foram deixadas no ecossistema, com prejuízos à integridade física e mental de pessoas e animais, bem como degradações ao ambiente que transcendem a geração atual.

A fase reflexiva, como visto anteriormente, demanda a análise e reflexão dessas consequências negativas, sejam elas previsíveis ou imprevisíveis, advindas dessa evolução técnico-econômica da primeira fase da modernização. Levanta-se a discussão sobre os danos e a responsabilização dos agentes do desenvolvimento, bem como a prevenção e precaução dos riscos, a fim de alcançar um desenvolvimento sustentável.

\subsection{Princípio da responsabilidade - Hans Jonas}

Hans Jonas, filósofo alemão, em sua obra "O princípio responsabilidade” (2006, p. 17-18) propõe a superação da ética tradicional que se fundava apenas dentro dos limites do ser humano, não afetando a natureza não humana, para enfrentar a necessidade de uma nova ética para a civilização tecnológica.

O princípio ético fundamental, nesta senda, teria o preceito de que a existência ou a essência do homem jamais podem ser transformadas em apostas do agir, pois não se permite arriscar diante da incerteza, e obriga incondicionalmente o dever de prudência moral como mandamento irrecusável, assumindo-se responsabilidade e prudência no cerne do agir (JONAS, 2006, p. 88). 
Ao homem este dever de prudência moral apresentado como prioritário, para o autor, inclui também o dever relativo à natureza, como condição essencial de continuidade de sua própria existência (JONAS, 2006, p. 230).

Reconhece-se a responsabilidade que se tem em garantir a existência da vida planetária como um todo, a fim de se compreender o quanto todas as formas de vida se tornam vulneráveis aos problemas criados pelos seres humanos.

Com o objetivo de se moldar o comportamento humano perante o ambiente e à vida em sentido amplo é que se permite que a Administração Pública aplique penalidades aos infratores, como forma de delimitação de conduta.

Nas palavras de Souza-Lima e Zambon (2017, p. 292) o cumprimento das disposições constitucionais quanto ao objetivo da República de desenvolvimento, perpassa pela revisão do modelo de civilização, o qual historicamente foi pautado no desenvolvimento a curto prazo, levando em consideração unicamente o progresso econômico imediato.

A obra de Hans Jonas impulsiona ao pensamento de que uma vida autêntica depende, invariavelmente, das relações humanas com o próprio ambiente habitável, ou seja, não é somente a preocupação de proteger a vida humana, mas também toda a biosfera e a sua complexidade (WANDSCHEER; MYSZCZUK; CAVALHEIRO, 2011, p. 46).

Imaginando-se eventuais desastres ambientais advindos dos avanços tecnológicos é que Hans Jonas (2006, p. 235) enaltece a nova ética, na direção de que o homem, embora possua uma diversidade de possibilidades para o desenvolvimento social e econômico, não deve deixar de visualizar o possível prejuízo às demais formas de vida - que não humanas, mas que também detém o direito de dignidade - e as gerações futuras - que também possuem o direito a uma vida digna e com qualidade ecológica.

\subsection{Responsabilidade ambiental da empresa}

A percepção da importância da questão ambiental tem afetado as empresas, por figurarem como um dos atores sociais, pois diante da evolução da conscientização quanto aos danos já causados no meio ambiente, os negócios jurídicos passam pelos temas ambientais.

A evolução das perspectivas empresariais dos temas ambientais ocorreu em razão dos alarmes provocados pelos acidentes ecológicos de repercussão local, nacional e mundial, influenciando de forma significativa o comportamento empresarial e, consequentemente, os negócios a curto, médio e longo prazo (JONAS, 2006, p. 194).

Em busca de uma maior implementação de condutas ambientalmente responsáveis as empresas passam a adotar uma série de medidas a fim de demonstrar à sociedade que cumprem a legislação ambiental e que participam de processos sociais e ecológicos, a fim de obter legitimidade social. Com isso, ao papel econômico, agrega-se o da responsabilidade social, no qual se inclui a dimensão ambiental.

A falta de responsabilidade ambiental pode se manifestar de diversas formas, como a deposição de material tóxico em áreas sem controle ou regulamentação, o corte abusivo de árvores de matas nativas, o despejo de resíduos tóxicos em rios e lagos, as práticas ambientais 
obscenas na cadeia produtiva (ignorando aquilo que os fornecedores fazem em relação às questões ambientais sem envolvimento ou fiscalização da empresa líder), queimadas noturnas de cana-de-açúcar, dentre outras (JONAS, 2006, p. 199).

A atuação empresarial com responsabilidade socioambiental suplanta uma tendência mercadológica que transforma gradualmente as ações corporativas (RAMIRES JUNIOR, 2018, p. 139).

O sistema capitalista de modelo econômico apresenta grandes ameaças à sociedade no que se refere aos recursos naturais. $\mathrm{O}$ meio ambiente, como bem jurídico difuso de uso comum do povo, sofre fortes danos advindos da ação humana, sendo resultado do objetivo potencializado de geração de lucro e redução de custos de produção, o que invoca a atuação da população e do Poder Público, enquanto atores do desenvolvimento sustentável, para criar condições de prevenção, fiscalização e punição dos infratores (SOARES; CAMPOS, 2019, p. 18). Com isso, surgem as três formas de responsabilização daqueles que produzem o dano ambiental, as quais, no ordenamento jurídico brasileiro se apresenta em três esferas: civil, penal e administrativa.

\section{A RESPONSABILIDADE ADMINISTRATIVA POR DANO AMBIENTAL}

Especificamente no espectro da responsabilidade administrativa, as maneiras de aferição das responsabilidades pelo dano ambiental refletem no ordenamento e na prática jurídica a fim de se averiguar a incidência da teoria subjetiva ou objetiva, observando se a culpabilidade seria elemento constitutivo da imputação infracional administrativa.

A responsabilidade administrativa exercida pelo Poder Executivo, decorre do poder de polícia sancionador do Estado, o qual é definido pelo artigo 78 do Código Tributário Nacional como sendo a atividade da Administração Pública que limita ou disciplina direitos, interesses ou liberdades, regula a prática de ato ou a abstenção de fato, em razão do interesse público relacionado à segurança, à higiene, à ordem, aos costumes, à disciplina da produção e do mercado ao exercício de atividades econômicas que dependem de concessão ou autorização do Poder Público, à tranquilidade pública ou ao respeito à propriedade e aos direitos individuais ou coletivos.

A responsabilidade administrativa por dano ambiental possui natureza preventiva e repressiva, sendo que esta última se concretiza na imposição de sanção, mediante o devido processo administrativo sancionador e, tal como ditam os princípios do direito administrativo, deve observar estritamente os princípios da legalidade, tipicidade, impessoalidade, moralidade, proporcionalidade e culpabilidade (PEREIRA, 2012, p. 370), sendo este último matéria de controvérsia debatida na doutrina e na jurisprudência como se verá a diante.

O ilícito administrativo-ambiental se submete ao regime jurídico do Direito Administrativo, observando o princípio da legalidade e o da tipicidade (VITTA, 2008, p. 152). E, por se tratar de violação ao bem jurídico do meio ambiente, não deve descartar as regras e princípios do Direito Ambiental.

O poder de polícia administrativa ambiental, consoante destaca Milaré, é exercida a serviço da comunidade e na defesa do patrimônio público e, para tanto, deve deter o caráter 
pedagógico adequado. Muitos desvios nocivos ao meio ambiente advêm de antigos vícios culturais da sociedade, resultado da falta de consciência sobre problemas e exigências ambientais. Neste sentido, a polícia ambiental sobrepõe educar a punir, sendo que são muitos os casos em que a punição integra o cunho pedagógico (MILARÉ, 2016, p. 113).

No direito administrativo sancionador, para além da atuação estatal na esfera penal, o Poder Público possui atribuição administrativa mais adequada à realidade ambiental, pois se relaciona mais intimamente com o âmbito empresarial, a fim de coordenar a atividade econômica com cunho educativo e pedagógico (TORELLI PINTO, 2014, p. 62).

Neste sentido, a atuação da Administração Pública, com base na legalidade, impessoalidade, moralidade e proporcionalidade apresenta natureza preventiva e repressiva, as quais elencam o cunho pedagógico em matéria ambiental, por se tratar de direito afeto à coletividade, concretizando tal atuação mediante identificação de infração administrativa e aplicando as sanções cabível.

O cometimento plural de infrações autoriza a autoridade administrativa a aplicar, de forma cumulativa as sanções cominadas a cada ato ilícito, e, com base no princípio da proporcionalidade, às infrações mais leves são aplicáveis penalidades mais brandas, sem perder o cunho educativo da medida.

O debate surge na análise da culpa ou dolo para aplicação da sanção administrativa. Ao longo da legislação ordinária, vislumbra-se a preocupação que o legislador teve para destacar, de forma expressa, que pelo dano ambiental, a responsabilidade civil é objetiva, independente de culpa ou dolo, e que pelo crime ambiental, a teoria da culpabilidade e o princípio da pessoalidade são observados, indicando a responsabilidade subjetiva.

No entanto, não há indicação legislativa expressa que consagre se a responsabilidade administrativa pelo dano ambiental é subjetiva ou objetiva.

O posicionamento quanto à subjetividade da responsabilidade administrativa ambiental é defendido por Fortunato Bim (2010, p. 33-70), o qual salienta ser impossível a aplicação da pena administrativa, na mesma vertente da esfera penal, na ausência de culpa, por meio de negligência, imprudência, imperícia, ou dolo, na seara ambiental.

Em defesa da posição subjetiva da responsabilidade administrativa ambiental, aventam-se os incisos LV e LVII, da Constituição Cidadã, nos quais são assegurados o devido processo legal, seja ele administrativo ou judicial, a ampla defesa e o contraditório, bem como a presunção de inocência. Assim, a corrente que aplica a responsabilidade subjetiva (MILARÉ, 2016, p. 122) advoga no sentido de que caso fossem desconsideradas tais garantias, haveria violação a estes direitos fundamentais.

Por outro lado, em defesa da posição objetiva, o pressuposto da atuação administrativa em caso de dano ambiental se concentra na ocorrência da infração em subsunção com a conduta do agente, sejam elas genéricas (artigo 70 da Lei n. 9.605/1998) ou específicas (Decreto n. 6.514/2008) (CARVALHO, 2007).

Meirelles lecionava que a multa administrativa seria de natureza objetiva e assim se torna devida independentemente de dolo ou culpa do infrator. Para o autor, a infração administrativa resulta em todo ato que viole o ordenamento jurídico no tocante ao uso, gozo, promoção e recuperação do meio ambiente, sem qualquer condicionante de voluntariedade do agente (MEIRELLES, 2011, p. 232). 
De outra banda, na esteira do que se mencionou no item anterior, Milaré destaca a viabilidade de se adotar uma teoria da culpa presumida, em caso de responsabilidade administrativa por dano ambiental (2011).

Argumenta o autor, que a Lei Ambiental Argentina n. $25.675 / 2020^{3}$ possui a previsão de que um comportamento que contrarie uma norma ambiental presume, juris tantum, a responsabilidade do infrator. O agente, neste caso, deverá demonstrar, com a inversão do ônus da prova, que não agiu de forma culposa, de modo que, ao não se desincumbir deste ônus, será responsabilizado de forma presumida.

Note-se que a teoria da culpa presumida dita um caráter objetivo na aplicação da sanção, adotando-se o caminho inverso, afastando a imediata discussão da culpabilidade, preterindo o elemento culpa à última possibilidade a ser aventada como matéria de defesa.

Philippi Junior, Freitas e Spínola (2016, p. 870), destacam que a mera previsão da conduta violada incita a atuação administrativa do Poder Público para a aplicação da sanção. Neste cenário, descabe a discussão de houve ou não a intenção ou o se era possível de se evitar o dano.

Para os autores, "a exigência de comprovação de dolo ou culpa para a imposição de sanções administrativas é totalmente contrária aos preceitos normativos existentes no nosso ordenamento jurídico ambiental” (PHILIPPI JUNIOR, FREITAS, SPÍNOLA, 2016, p. 871).

Padilha (2010, p. 295) destaca que não há o que se falar em elemento subjetivo para a configuração da responsabilidade administrativa, uma vez que a Lei n. 9.605/1998 não exigiu a culpabilidade como requisito, sendo que em havendo intenção dolosa ou culposa, poderia haver agravamento na proporcionalidade da sanção a ser aplicada, remontando o cenário do cunho pedagógico da medida.

Nesta senda, não havia possibilidade de excludentes de ilicitude, uma vez que na esfera penal, em razão de estarem previstas no texto legal, tais excludentes resultariam no afastamento da aplicação da pena (PADILHA 2010, p. 295). A responsabilização administrativa, assim, mantém o caráter repressivo e educativo, independente de culpa e independente de excludentes de ilicitude, em prol da sociedade.

Tendo em vista que o dano ambiental afeta toda a sociedade (presentes e futuras gerações), a qual figura como vítima de ato com proporções, muitas vezes, incalculáveis, tamanha a gravidade do prejuízo à qualidade de vida, o condão da atuação do Poder Público, afasta os debates que fragilizem a proteção ambiental, diante do caráter educativo, pedagógico, preventivo e repressor da sanção administrativa.

Em termos pragmáticos, importante trazer à baila o debate instalado em julgado emblemático, que apresentou a divergência na jurisprudência do Superior Tribunal de Justiça, sobre a matéria da culpabilidade na responsabilidade administrativa por dano ambiental.

\footnotetext{
3 "Articulo 29. - La exención de responsabilidad sólo se producirá acreditando que, a pesar de haberse adoptado todas las medidas destinadas a evitarlo y sin mediar culpa concurrente del responsable, los daños se produjeron por culpa exclusiva de la víctima o de un tercero por quien no debe responder. La responsabilidad civil o penal, por daño ambiental, es independiente de la administrativa. Se presume iuris tantum la responsabilidad del autor del daño ambiental, si existen infracciones a las normas ambientales administrativas." Disponível em: <https://www.argentina.gob.ar/normativa/nacional/ley-25675-79980/texto>. Acesso em: 21.Jun.2020.
} 


\subsection{Jurisprudência Superior Tribunal de Justiça - Recurso Especial 1.318.051 - RJ}

Em 14/11/2018, o Relator Ministro Mauro Campbell Marques proferiu seu voto para conhecer dos Embargos de Divergência e, no mérito, dar-lhe, provimento.

No voto do Relator foi aventado que a jurisprudência do Superior Tribunal de Justiça ao julgar casos análogos, assentou que a responsabilidade administrativa ambiental é subjetiva.

Afirmou o relator, que o mesmo já havia proferido outras decisões, inclusive como relator, as quais colacionou no corpo da de seu voto. E, em síntese, salientou que a empresa Embargante, por não ter tido participação direta no acidente, não deve ter contra si a autuação de infração imposta pela autoridade municipal.

Das decisões citadas no voto do Ministro Relator, extrai-se que houve fragmentação da análise da seguinte forma: a aplicação e a execução das penas se limitariam aos transgressores; ao passo que a reparação por dano ambiental, de cunho civil, abarca todos os poluidores, podendo ser esta pessoa física ou jurídica, de direito público ou privado, que contribuiu direta ou indiretamente para a ocorrência do dano ambiental.

Na sessão de julgamento, o Ministro Herman Benjamin pediu vistas dos autos, sendo a sessão adiada para 08/05/2019. E, na referida sessão, houve unanimidade na votação, e os Ministros Assusete Magalhães, Sérgio Kukina, Regina Helena Costa, Gurgel de Faria, Francisco Falcão, Herman Benjamin (voto-vista), Napoleão Nunes Maia Filho e $\mathrm{Og}$ Fernandes votaram com o Sr. Ministro Relator.

Considerando que o Ministro Herman Bejamin pediu vistas dos autos, em seu voto fundamentou a responsabilidade subjetiva para imposição de penalidade administrativa por infração ao meio ambiente.

Salientou que o artigo $14, \S 1^{\circ}$, da Lei 6.938/1981 preconiza que a indenização ou reparação dos danos ambientais não afasta a aplicação de sanções administrativas, e destaca que a indenização ou reparação do dano prescindem da culpa, o que não ocorre às sanções administrativas. Neste diapasão, não se confunde o direito administrativo sancionador com a responsabilidade civil ambiental, tampouco autorizando atribuir responsabilidade do autuado por fato de terceiro.

Diante da decisão proferida nos Embargos de Divergência, o Superior Tribunal de Justiça sedimentou a matéria, estancando que a responsabilidade administrativa por dano ambiental é subjetiva, cabendo apenas à figura do infrator direto.

Todavia a sedimentação da matéria pela Corte parece se adequar à sistemática apenas das infrações administrativas de modo geral, sem se atentar ao subsistema da responsabilidade administrativa ambiental, que se compõe tanto pelo regramento direito administrativo, quanto do direito ambiental, uma vez que o bem jurídico tutelado - meio ambiente - transcende às preocupações procedimentais, alcançando formas e números incalculáveis de vida. 


\subsection{Considerações sobre o entendimento do Superior Tribunal de Justiça}

A sedimentação da jurisprudência do Superior Tribunal de Justiça, pela aplicação da teoria subjetiva da responsabilidade administrativa por dano ambiental possui íntima ligação com a individualização da pena do infrator.

A limitação da pessoalidade posta pela Corte à figura do infrator direto que comete o ilícito ambiental visa atender aos preceitos do princípio da pessoalidade, de modo que a sanção administrativa se aproximaria do Direito Penal, o qual detém o caráter repressivo.

Entretanto, as infrações e sanções administrativas em matéria ambiental possuem características específicas, considerando a proteção de um direito difuso, com dimensões intangíveis e princípios próprios. Ao assimilar a sanção administrativa à sanção penal haveria fusão de princípios que resultaria da anulação de um dos ramos ou na criação de um sistema único e macro de punição.

No entanto, o legislador distinguiu as esferas de responsabilidade, motivo pelo qual não há que se falar em aplicar institutos específicos do Direito Peal no sistema do Direito Administrativo, sob pena de anulação de um dos dois sistemas de responsabilização.

Sob o prisma da responsabilidade administrativa por dano ambiental, o bem jurídico tutelado é o meio ambiente, o qual possui o manto de proteção do Direito Ambiental, com princípios específicos do direito material, quais sejam o da prevenção, precaução e poluidor pagador.

O entendimento do órgão jurisdicional, fixou a aplicação de sanção apenas ao agente direto, sem se preocupar com questões como o princípio da precaução e da prevenção do agente indireto.

Diante do dano ao bem jurídico do meio ambiente, a interpretação da norma não deve se restringir apenas às regras e princípios do Direito Administrativo (ou do Direto Penal), caso contrário, seria o mesmo que amparar o infrator em suas garantias individuais às custas do meio ambiente, que constitui direito da coletividade.

O próprio princípio do Direito Administrativo de predominância do interesse público sobre o interesse privado estaria sendo violado. Ou seja, investir-se-ia na discussão de colisão de direitos individuais versus direito coletivo.

Seria o mesmo que dar garantias aos atuais infratores às custas das demais formas de vida do ecossistema, para além do comprometimento da qualidade de vida das futuras gerações.

Não se defende a livre e genérica responsabilização neste aspecto, mas sim o cumprimento do artigo 225 da Constituição Federal de 1988, quando atribui à coletividade o dever constitucional de defender e preservar o meio ambiente.

No tocante ao cunho educativo da medida administrativa, claramente se observar que este deixa de ser o centro da norma jurídica, uma vez que os próprios Ministros da Corte, quando da prolação de seus votos, mencionam decisões proferidas anteriormente em casos análogos. 
Ou seja, depreende-se que a investida na teoria subjetiva, tem resultado na reincidência de atos de degradação ambiental, sejam pelos mesmos agentes ou por agentes diversos.

O caso dos acidentes na cidade de Mariana em Minas Gerais em 2015 e em Brumadinho, também em Minas Gerais em 2019 revelam exemplos cristalinos de ineficiência das medidas de responsabilização de empresas exploradoras de atividade econômica. Os incêndios no Pantanal em 2020 seguem a mesma lógica. Sem a responsabilidade administrativa objetiva não há como se punir a pessoa jurídica por dano ambiental, pois para além do Poder de Polícia ambiental não ser onipresente, a pessoa jurídica é abstração do direito não possuindo vontade, tal como se reconhece e aplica em relação às pessoas naturais.

O contexto fático do dano ambiental, com as suas consequentes penalizações em todas as esferas (civil, penal e administrativa) deveriam se mostrar eficientes na moldagem de um desenvolvimento sustentável. Em verdade, se reduzem a normas jurídicas com aberturas interpretativas que esquivam as empresas de adotarem novos comportamentos éticos preocupados com o ecossistema, posto que o vetusto modelo ainda está focado na responsabilidade subjetiva da pessoa natural.

A penalização pelo dano ambiental, diante do caráter pedagógico-repressivo, visa obstar a reincidência do fato danoso, não se limitando à pedagogia frente ao infrator, o qual deveria servir ao intuito educativo exemplar de defesa ao bem jurídico coletivo (natureza).

A dificuldade de restauração do status quo ambiental impede que se admita 'autorização tácita' de perpetuação de ações empresariais despreocupadas com o meio ambiente, mediante pagamento de indenização reparatória - interpretação equivocada que se atribui ao princípio do poluidor pagador.

$\mathrm{O}$ atributo do poder de polícia de coercibilidade, principalmente na esfera ambiental, defere o direito fundamental prestacional e de defesa que a sociedade detém em face do Poder Público na defesa do meio ambiente.

Ao se abrir espaço para discussões de culpabilidade na aplicação da pena administrativa, deixa de cumprir o papel social do atributo de coerção do poder de polícia concedido à autoridade administrativa.

Em transcendência à atuação punitiva, e considerando a necessidade de instalação de um desenvolvimento sustentável, o Direito Administrativo sancionador se presta à função pedagógica de adequar a realidade ambiental, a fim de coordenar a atividade econômica de maneira educativa.

O meio ambiente ecologicamente equilibrado, por constituir direito da coletividade, transborda às preocupações contratuais de responsabilidade entre os contratantes, razão pela qual a pluralidade de agentes envolvidos no ato que se desdobrou o dano ambiental, enseja a responsabilização plural de todos os envolvidos na conduta (sem obstar o direito regressivo no âmbito da relação contratual).

A responsabilidade administrativa por dano ambiental versa, portanto, sobre a responsividade estatal, por intermédio da qual a Administração Pública entrega resposta à sociedade com responsabilização do poluente independente de culpa ou dolo. Concretiza, assim, o direito fundamental de prestação e de defesa na preservação ecológica, impondo à coletividade (administrados e os potenciais poluidores) a incumbência de readequar a cultura 
social de degradação ambiental em busca de um desenvolvimento sustentável, frente à sociedade de risco instalada pelas atividades econômicas no uso dos recursos naturais.

\section{CONCLUSÃO}

A presente pesquisa enfrentou a dicotomia existente da doutrina e na jurisprudência no que se refere à responsabilidade administrativa pela empresa privada, por dano ambiental.

Os direitos fundamentais estacam a dimensão do meio ambiente como elemento essencial à vida digna. $\mathrm{O}$ ordenamento jurídico brasileiro, ao positivar o meio ambiente na ordem constitucional, lança este ao patamar de direito fundamental.

Da hermenêutica constitucional estampada no artigo 225 da Carta Maior, denota-se que o meio ambiente se insere no ordenamento jurídico como direito fundamental, ligado ao princípio da dignidade da pessoa humana, podendo ser classificado, dentre outras naturezas, como um direito prestacional e de defesa, pois requer atividade estatal para exigir cuidados ambientais, com limitação do uso dos recursos naturais por outros particulares, assim como limita a própria atuação governamental quanto à exploração ecológica.

A dignidade, embora estampada na Constituição Federal de 1988 como atributo da vida humana, emerge a necessidade de se compreender a dimensão ecológica da dignidade da pessoa humana. Ou seja, para além de centralização da vida humana, passa-se a perceber a valoração de todas as formas de vida, do que se extrai a dimensão ecológica do princípio da dignidade da pessoa humana, cujas preocupações se concentram na vida como um todo, abrangendo todas as formas de vida, cuidando-se das presentes e das futuras gerações.

Nesta senda, o princípio da responsabilidade, proposto por Hans Jonas, destaca a superação da ética tradicional calcada no antropocentrismo e a implementação de uma ética preocupada com o futuro e que, para que este futuro aconteça, com devido desenvolvimento econômico e social, é imprescindível o cuidado com a qualidade ecológica, com todas as formas de vida, em busca de se realize um desenvolvimento sustentável.

A responsabilidade ambiental empresarial demonstra o verdadeiro compromisso da sociedade empresária com o desenvolvimento sustentável. Traduz a adoção de ações pela empresa que transcendem às exigências legais e de mercado referentes aos parceiros comerciais e à publicidade e propaganda. A empresa ambientalmente responsável assume postura voluntária em iniciativas, programas e propostas que busquem a manutenção dos recursos naturais livre de contaminação para preservação de todas as formas de vida.

$\mathrm{Na}$ medida em que a empresa não realiza medidas de prevenção do dano ambiental, o acidente que causa degradação ambiental gera ao poluidor, de acordo com o ordenamento brasileiro, a responsabilidade tríplice, com dever de reparação os danos, além de responder nas esferas penal e administrativa.

A tríplice responsabilidade constitui resultado da dimensão do meio ambiente, enquanto direito fundamental pertencente à toda a coletividade, trata-se de resposta à sociedade. A responsabilidade administrativa, concretiza-se através do poder de polícia, o qual é exercido com natureza preventiva e, ao mesmo tempo, repressiva. 
A doutrina e a jurisprudência divergem, porém, no tocante ao elemento culpa ou dolo na esfera administrativa, se esse deve ou não ser analisado em caso de infração (ou dano) ambiental.

O Superior Tribunal de Justiça enfrentou julgamento emblemático (Recurso Especial 1.318.051 - RJ) que, a priori, consolidou o entendimento da Corte sobre o elemento subjetivo na aplicação da sanção administrativa.

A decisão colegiada da Corte levou em consideração os atributos da sanção administrativa e o princípio da pessoalidade, aproximando o exame aos atributos da culpabilidade do Direito Penal.

Todavia, a infração administrativa por dano ambiental envolve o estudo de regras e princípios tanto do Direito Administrativo quanto do Direito Ambiental. Os princípios fundamentais do Direito Ambiental sequer foram mencionados no julgamento do Superior Tribunal de Justiça.

Conforme salientado no desenvolvimento da presente pesquisa, o meio ambiente ecologicamente equilibrado constitui direito fundamental prestacional e de defesa.

O poder de polícia em matéria ambiental, deve observar o cunho pedagógico e exemplar da medida a fim de se evitar a reincidência da degradação ambiental. E, aliado a isso, a predominância do interesse público sobre o interesse privado releva o cunho repressivo e educativo da sanção administrativa.

O meio ambiente, por constituir direito da coletividade, transcende às preocupações contratuais. A posição de direito fundamental do meio ambiente ecologicamente equilibrado no Estado Socioambiental, e a consolidação da dimensão ecológica da dignidade da pessoa humana, não deve perder a eficácia quando da ação estatal no caso concreto.

Portanto, a responsabilidade administrativa objetiva por dano ambiental consiste na responsividade estatal, que entrega à sociedade resposta adequada, porquanto em consonância filosófica (princípio responsabilidade), principiológica (princípios ambientais), sistêmica e finalística contra o poluidor pessoa jurídica, visando a concretização do direito fundamental de prestação e de defesa na preservação ecológica, na empreitada de readequar a cultura de degradação ambiental, contra a impunidade, em busca de um desenvolvimento sustentável.

\section{REFERÊNCIAS}

ALENCASTRO, Mario Sergio Cunha. Empresa, ambiente e sociedade: introdução à gestão ambiental. Curitiba: Editora Intersaberes, 2012.

AMADO, Frederico Augusto Di Trindade. Direito ambiental esquematizado. $-3^{\mathrm{a}}$ ed. Rio de Janeiro: Forense; São Paulo: Método. 2012.

BENJAMIN, Antonio Herman. A natureza do direito brasileiro: coisa, sujeito ou nada disso.

In. Revista do Programa de Pós-Graduação em Direito da UFC, p. 79-96, 2011/1.

Disponível em: <http://periodicos.ufc.br/nomos/article/view/398/380>. Acesso em:

17/05/2020. 
BENJAMIN, Antonio Herman. O meio ambiente na constituição federal de 1988. In. Informativo Jurídico da Biblioteca Ministro Oscar Saraiva, v. 19, n. 1, jan./jun. 2008.

BERTONCINI, Mateus Eduardo Siqueira Nunes; MÜLLER, Ane Elize Deonara. O balanço social como instrumento jurídico da cidadania. In. Revista Jurídica - Unicuritiba. v. 1 , $n$. 28. 2012, p. 465-485. Disponível em:

<http://revista.unicuritiba.edu.br/index.php/RevJur/article/view/424/329>. Acesso em: 17.Mai.2020.

BIM, Eduardo Fortunato. O mito da responsabilidade objetiva no direito ambiental sancionador: imprescindibilidade da culpa nas infrações ambientais. Revista de Direito Ambiental, v. 57, ano 15, jan./mar. 2010.

BRASIL. Constituição da República Federativa do Brasil de 1988. Disponível em: <http://www.planalto.gov.br/ccivil_03/constituicao/constituicao.htm>. Acesso em: 19.Mar.2020.

BRASIL. Lei n. 8.078, de 11 de setembro de 1990. Disponível em: < http://www.planalto.gov.br/ccivil_03/leis/L8078compilado.htm>. Acesso em: 07.Mar. 2020.

BRASIL. Lei n. 9.605, de 12 de fevereiro de 1998. Disponível em:

<http://www.planalto.gov.br/ccivil_03/leis/19605.htm>. Acesso em: 19.Mar.2020

BRASIL. Lei $\mathbf{n}^{\circ}$ 6.938, de 31 de agosto de 1981. Disponível em:

<http://www.planalto.gov.br/ccivil_03/Leis/L6938compilada.htm>. Acesso em: 19.Mar.2020.

Comissão Mundial sobre Meio Ambiente e Desenvolvimento. Nosso futuro comum. $2^{\mathrm{a}}$. ed. São Paulo. Editora da Fundação Getúlio Vargas, 1991.

FIORILO, Celso Antonio Pacheco. Curso de direito ambiental. 19a ed. São Paulo: Saraiva, 2019.

JONAS, Hans. O princípio da responsabilidade: Ensaio de uma ética para a civilização. Tradução do original alemão Marijane Lisboa, Luiz Barros Montez. Rio de Janeiro: Contraponto: Ed. PUC-Rio, 2006.

KANT, Emmanuel. Tradução por J. rodrigues de Merege. Crítica da Razão Pura. Disponível em: <http://www.dominiopublico.gov.br/download/texto/cv000016.pdf>. Acesso em: 17.Mai.2020.

MACHADO, Paulo Affonso Leme. Direito ambiental brasileiro. 18.ed. São Paulo: Malheiros, 2010.

MEIRELLES, Hely Lopes. Direito administrativo brasileiro. 33.ed. São Paulo: Malheiros, 2011; CARVALHO, Delton Winter de. A responsabilidade administrativa no estado democrático ambiental. In. Revista da Associação dos juízes do Rio Grande do Sul, v. 34, p. 79-97, n. 108. Dezembro de 2007.

MILARÉ, Édis. Reação jurídica à danosidade ambiental: contribuição para o delineamento de um microssistema de responsabilidade. Tese de Doutorado em Direto das Relações Sociais. Pontifícia Universidade Católica de São Paulo. 2016. Disponível em: <https://tede.pucsp.br/bitstream/handle/18874/2/\%C3\%89dis\%20Milar\%C3\%A9.pdf>. Acesso em: 21.Jun.2020. 
MIRANDA, Fernando Silveira Melo Plentz; DALLA DEA, Carlos Roque. Aspectos Jurídicos do Direito Ambiental e a Responsabilidade Civil por Danos Ambientais. In. Revista

Eletrônica Direito, Justiça e Cidadania. Volume 2, nº 1, 2011.

NEGRI SOARES, M.; GISELA CAMPOS, M. Compliance Na Realização Da Função Social Da Empresa. Revista Percurso, [s. 1.], v. 1, n. 28, p. 1-21, 2019. DOI

10.6084/m9.figshare.8340917. Disponível em:

http://search.ebscohost.com/login.aspx?direct=true\&db=foh\&AN=137356023\&lang=pt-

br\&site=ehost-live. Acesso em: 13 jun. 2020.

NONINO, M. E.; FERREIRA, D. O Recrudescimento Do Direito Administrativo

Sancionador Na Sociedade De Riscos. Revista Percurso, [s. 1.], v. 2, n. 19, p. 238-258, 2016. Disponível em:

http://search.ebscohost.com/login.aspx?direct=true \&db=foh\&AN=125613919\&lang=ptbr\&site=ehost-live. Acesso em: 19 abr. 2020.

OLIVEIRA, Fabiano Melo Gonçalves de. Direito Ambiental. $2^{\mathrm{a}}$ ed. Rio de Janeiro: Forense; São Paulo: MÉTODO, 2017.

PADILHA, Norma Sueli. Fundamentos constitucionais do direito ambiental brasileiro.

Rio de Janeiro: Elsevier. 2010.

PADILHA, Norma Sueli. Fundamentos constitucionais do direito ambiental brasileiro.

Rio de Janeiro: Elsevier. 2010.

PAULO RAMIRES JR, S. et al. Responsabilidade Socioambiental E O Comportamento Dos Clientes Na Decisão De Compra. Revista de Administração da UNIMEP, [s. 1.], v. 16, n. 2, p. 132-156, 2018. Disponível em:

http://search.ebscohost.com/login.aspx?direct=true \&db=foh\&AN=132648504\&lang=ptbr\&site=ehost-live. Acesso em: 13 jun. 2020.

PEREIRA, Luciana Vianna. Responsabilidade administrativa ambiental - novos paradigmas adotados pela jurisprudência. Revista de direito ambiental - RDA. v. 17, n. 66, abriljulho.2012, p. 361-382. São Paulo: Editora Revista dos Tribunais.

PHILIPPI JUNIOR, Arlindo; FREITAS, Vladimir Passos de; SPÍNDOLA, Ana Luiza Silva. Direito e sustentabilidade. Barueri: Editora Manole Ltda. 2016.

REIS, C.; BAPTISTA SILVA CARICATI, F.; GIUBLIN, P. Sociedade De Risco, Definição Democrática Do Risco E Segurança Jurídica. Revista Percurso, [s. 1.], v. 2, n. 25, p. 448471, 2018. DOI 10.6084/m9.figshare.7423712. Disponível em:

http://search.ebscohost.com/login.aspx?direct=true \&db=foh\&AN=134157948\&lang=ptbr\&site=ehost-live. Acesso em: 18 abr. 2020.

SARLET, Ingo Wolfgang; FENSTERSEIFER, Tiago. Direito constitucional ambiental. $4^{\mathrm{a}}$ ed. São Paulo: Editora Revista dos Tribunais. 2014.

SOUZA-LIMA, José Edmilson de; BARROS, Ellen Galliano de. Tutela administrativa de barragens de rejeitos de minérios: a tutela administrativa estatal. In. Revista Relações

Internacionais do Mundo Atual. v3, n. 24. 2019. Disponível em: http://revista.unicuritiba.edu.br/index.php/RIMA/article/view/3918/371372248. Acesso em: 17.Mai.2020. 
SOUZA-LIMA, José Edmilson de; ZAMBON, Paloma Carvalho. Logoterapia e sustentabilidade: responsabilidade e direito ao futuro. Revista Jurídica - Unicuritiba. vol.04, n $^{\circ}$.23, Curitiba, 2017. p. 287-305. Disponível em: <http://revista.unicuritiba.edu.br/index.php/percurso/article/view/2739/371371462>. Acesso em: 17.Mai.2020.

Superior Tribunal de Justiça. EREsp 1.318.051 - RJ (2012/0070152-3). Relator Ministro Mauro Campbell Marques. Publicado em: 12/06/2019, no DJe. Disponível em: < https://ww2.stj.jus.br/processo/pesquisa/?tipoPesquisa=tipoPesquisaNumeroRegistro\&termo= 201200701523\&totalRegistrosPorPagina=40\&aplicacao=processos.ea>. Acesso em:17.Mar.2020.

TORELLI PINTO, João Otávio. Responsabilidade administrativa da pessoa jurídica, Direito Penal para que? Revista Digital de Direito Administrativo. v. 1, n. 1, p. 52-68, 2014, DOI: https://doi.org/10.11606/issn.2319-0558.v1i1p52-68. Acesso em 20.Jun.2020.

VITTA, Heraldo Garcia. Responsabilidade civil e administrativa por dano ambiental. Editora Malheiros: São Paulo. 2008.

WANDSCHEER, Clarissa Bueno; MYSZCZUK, Ana Paula; CAVALHEIRO, Karyn Cristine. Atividade empresarial, responsabilidade social, accountability ambiental e sustentabilidade: uma análise a partir de Hans Jonas. Rio de Janeiro: Legis Augustus. v. 2, n. 2, p. 43-60, ago. 2011. 